\title{
Managing the Psycho-Social Vacuum of COVID-19 among Rural Learners through Ubuntu
}

\author{
Bunmi Isaiah Omodan \\ School of Education Studies, \\ University of the Free State, \\ South Africa
}

DOI: https://doi.org/10.36941/jesr-2020-0125

\begin{abstract}
The advent of COVID-19 has thrown the world in upheaval, most notably in the operationalisation of secondary schools. Observation, bodies of existing literature, and experience have shown that rural secondary school learners are disillusioned and uncertain on the future of their academic development amidst the "psychosocial" vagueness regarding their schooling and well-being. This study draws its background from South African teachers' perspectives and proposed Ubuntu as relational framework lensing through Transformative Paradigm to respond to the problem. Critical Emancipatory Research was adopted as a research design. Five secondary schools located in Thabo Mofutsanyane municipality of the Free State, South Africa, form the research site. Two teachers each were selected from the schools using the opportunistic selection approach. A semi-structured interview was used to collect data from the teachers on the challenges faced in managing learners during the pandemic and how to manage the effect of COVID-19 on the learners. Socio-thematic Analysis (StA) was used to analyse the data. The findings showed that learners in rural areas are disadvantaged through the poverty line, affected psycho-socially, and that the need for sociological and psychological supports for teachers and learners becomes expedient in the management of the vacuum created by COVID19. The study concluded that the principle of Ubuntu during and after COVID19 is a possible means to ameliorate the vacuum.
\end{abstract}

Keywords: COVID-19, Learners, Management, Rural secondary schools, Teachers, Ubuntu

\section{Introduction}

The whole world was recently stuck as a result of coronavirus pandemic, otherwise known as COVID19 which allegedly emanated from Wuhan State of China in late 2019 (Varalakshmi \& Arunachalam, 2020). The virus was confirmed as contractible through social intimacy and after that declared a pandemic by the World Health Organisation on March 30, 2020 (WHO, 2020a) because it attacks the respiratory system with various scientifically proven symptoms like sneezing, fever and cough (Wuhan Municipal Health and Health Commission, 2020). That is, the virus majorly and easily spreads by coughing and sneezing. It affects other people via close contact with the carrier. Based on the uncontrollable spread of COVID-19 to virtually all the countries of the world, the government of nations, including South Africa, has keyed into the stipulated measures such as social distancing, propounded by the World Health Organisation (WHO, 2020a) by shutting down the country to curtail the spread in South Africa. The government of South Africa in March 2020 announced what it tagged "a total shutdown" of all government parastatals, companies, education and industry, among others. 
Ebrahim, Ahmed, Gozzer, Schlagenhauf and Memish (2020) regarded this as an economic shutdown. The national lockdown, according to the South African president, becomes expedient as the only measure readily available to cure the virus. This is supported by the claim made by WHO (202ob) that the only approved measure against COVID-19 is social distancing, avoidance of social gathering and self-isolation.

The education system in South Africa seems to be attacked by the unexpected shutdown which affects not only higher education, also, primary and secondary education were caught in the same imbriglio.. Teachers, learners and school administrators were asked to stay at home. In order to compliment the shutdown, various provincial governments and municipalities came up with various alternative teaching and learning for schools, among which are teaching via radio, the Internet, among others. Amidst many criticisms against this alternative, arguments exist that the measures did not cater for all the learners, mainly those located in the disadvantaged communities (Omodan, 2020a). Rural secondary schools before the advent of COVID-19 were disadvantaged in terms of access to basic educational facilities, and accommodating changes (du Plessis \& Mestry, 2019). This complements the above argument that the provision of the government to cater for all students during COVID-19 was not inclusive enough. This trajectory, however, is against the stipulation of the South African School Act (Republic of South Africa, 1996) that the School Governing Bodies (SGB) should ensure that learners are provided with equal learning opportunities through inclusive governance. Various factors are responsible for the deplorable condition of public schools, more especially rural ones. These factors, according to Du Plessis \& Mestry (2019) and Hlalele (2012), are under development, lack of social and infrastructural facilities, and lack of financial and social support.

Having identified this as part of the problems facing the rural schools in the context of South Africa, the place of leaners as agents greatly affected is a point of concern for this study. That is, for learners who were previously at the disadvantaged position in the world of education competitiveness, what then happens to such learners when there is a pandemic that befalls the government and the school management is unaware of them? In this sense, stakeholders' experience, including myself, show that the learners are in a dilemma of what becomes of their education since the majority of them are unable to proceed as a result of the lockdown. This has not only affected the sociality of learners, but they are psychologically uncertain about their academic progress. In line with this, Hlalele (2012) argued that rural education in South Africa remains elusive and has failed to blend to the increasing need for social and mental change. Besides, the COVID-19 pandemic and the state of mind of learners regarding their studies are disturbing. Qiu et al. (2020) and Hirematha, Kowshik, Manjunathb \& Shettar (2020) stressed that the current pandemic in several ways had caused anxiety, panic disorder, and depression, consequently traceable to severe threats to lives and physical health in which learners are no exception. In this case, the stakeholders of the system, such as teachers, therefore, have a lot to do in response to this vacuum. The urgent response becomes expedient because the learners in the secondary schools, most especially those in lower grade levels such as grades 8,9 , 10, and 11, might be affected with a feeling of social and psychological uncertainty.

To respond to this, the preparedness of teachers to improving the psycho-sociality of learners to cope well with all the social and psychological threats of COVID-19 is of great concern. The stakeholders, most notably the teachers, who are the closest authority around the learners, must continue to recognise and be perceptive on how to manage the learners and their psycho-social predicament. From this perspective, the relationship between teachers and learners cannot be underrated because teacher-student relationships have a positive correlation between learners' social interaction and their academic performance (Omodan \& Tsotetsi, 2018). This kind of relationship was conceptualised by Luo, Deng and Zhang (2020) as a tool that can eradicate academic and social stressors among learners. Consequently, this also helps to improve teachers' managerial acumen not only to develop positive academics and behavioural outcomes but also to create an effective and efficient way of managing the effect of social stress on learners (Zendarski, et al., 2020; Zeea, De Breea, Hakvoortb, Koomena, 2020). To ensure teachers' proactiveness towards this argument, the space of oneness, unity, interrelatedness, love, and compassion among the teachers, students, and in between 
the teachers and students is fundamental. That is why Ubuntu as a theory with possession of such characteristics is expedient.

\subsection{Framing Ubuntu as a humanitarian approach to learners' management}

Historically, Ubuntu was coined from Xhosa words, "ubu" which mean "being" and "ntu" which means "human" (Ramose, 1999; Omodan \& Tsotetsi, 2019). In the exploration of Tworeck, Hemminga, Huber \& Dhillon (2015), Ubuntu was equated to being "humane." To complement the humanity in these definitions, Khomba (2011) and Omodan (2019b) viewed Ubuntu as a collaborative philosophy where people see themselves as one despite their diversities. That is, the existence of a human being depends on others. Taking from these definitions, the principle of Ubuntu, therefore, leverage on the adage that; a person is a person, through others (Lefa, 2015), which means that human beings do not and/or cannot exist without others. This is to say that Ubuntu is a way of life and the living of the people within their togetherness for the purpose of oneness where everyone is important and treated as such, regardless of their differences. This was conceptualised by Omodan and Dube (2020) as an Africanised way of livelihood. Afrocentricism, in this sense, is synonymous with selfless services, caring for others, respecting and protecting others from dangers (Msila, 2008). In the same vein, Ubuntu philosophy preaches humanness, humanity, and morality for social relatedness and a person's well-being, leading to a better quality of life and a better community (Jolley, 2011).

The above show that Ubuntu and Ubuntuism is a way of life that brings common people together as one, in oneness and for their development. Tutu (1999) support that Ubuntu philosophy solidifies people with common goals in a jointly and non-discriminatory manner. I, therefore, argue that Ubuntu is an apostle of dignity, empathy, oneness and generosity, which, according to Nzimakwe (2014), is a perfect way of managing disparities in peoples' relationships. This is to say that Ubuntu could produce collaboration, corporation, trust, and respect between students and teachers towards achieving the aims and objectives of teaching and learning. Other social and psychological needs in the classroom are certain because Ubuntu ensures interdependency and inclusivity (Bolden, 2014) among the school stakeholders, which include learners. Hence, to ensure that learners are assisted to respond to the vacuum of COVID-19, the place of Ubuntu spirit as a better and progressive philosophy is pertinent to the management of the effect and the impact of COVID-19 on the learners. This is because interrelatedness and love among the stakeholders, most especially between the learners and the teachers, will strengthen their relationships and thereafter, produce positive outcomes with regard to progress and conducive learning environment for all.

Ubuntu is relevant for this study because it helps to pinpoint the characteristics needed by the teachers to cater for the psycho-social needs of learners to navigate the effect of COVID-19, not only on their studies, but also to enable them to balance their way of lives. This is confirmed by the argument of Hoffmann and Metz (2017) that Ubuntuism plays a pivotal role in gingering the capability of people towards themselves. I, therefore, join them in the same line of argument that the relationality embedded in Ubuntu will enhance teachers to show love and compassion for learners to be able to meet-up quickly with their advantaged counterparts. It will also enable the duo to work together without hitches and ease any psychological stress that might affect the students during the lockdown and or during the peak of the pandemic. The humanness in Ubuntu philosophy enables people (schools) to propose integrated ideas and foresight towards nurturing and developing ways to increase the potentials of the system (Sarpong, Bi \& Amankwah-Amoah, 2016) to respond to students' needs. To ensure the implementation of Ubuntu in secondary schools, the challenges hindering or that could impede teachers from giving the needed assistance to the learners, and the possible solutions to the problems inform the objectives of this study.

In order to solve the above problem, the following research question will pilot the study with an 
adequate concentration on teacher and Ubuntu perspectives;

- How can the psycho-social vacuum of COVID-19 among rural secondary school learners in South Africa be managed by the teachers using Ubuntu?

\subsection{Research Objectives}

In order to answer the above research questions, the following objectives guided the study research planning, process, and output stage;

1. This study explored possible challenges responsible for teachers to respond to the psychosocial vacuum of COVID-19 on learners.

2. The study investigated the possible solutions that could help learners navigate through the challenges.

\section{Methodology}

\subsection{Research Paradigm and Design}

This research is lensed through Transformative Paradigm (TP). TP is adopted because it complements the people's quest for transformation through collaboration as proposed by Ubuntu. This paradigm, at the same time, addresses the issue of social justice towards transformation and inclusivity to change the existing situation for better (Mertens, 2007). TP blends towards emancipating the researched from their perceived marginalisation. This is supported by the definition of Dube (2016) and Omodan (2020a) that the priority of TP is to change the existing status quo of the participants for better. This transformation, however, does not exist in abstract, but it involves the galvanisation of the researcher, the co-researchers and community people to challenge unequal powers (Hughes, 2020). To ensure that the current challenges facing learners are ameliorated by emancipating them from the existing psycho-social vagueness, the study adopted Critical Emancipatory Research (CER) as a research design. This was deemed necessary to enable the researcher and the researched to jointly get into the problem and collaboratively find solutions by interrogating the existing social vacuum among learners. This design is relevant to guide the study because it aims to reform, transform, emancipate and free the people from sociological and ideological enslavement (Dube and Hlalele, 2018; Omodan \& Dube, 2020). Therefore, it enables the researcher to engage in a transformative and participatory process of inquiry on the challenges and the possible solution that emancipate learners' social predicament as a result of COVID-19.

\subsection{Participants and Selection of Participants}

The participants for this study comprise teachers who are teaching in rurally located schools in Thabo Mofutsanyane municipality area of the Free State. They are selected based on their experience (minimum of 2 years) in rural schools. Their experience with the learners and their environment forms the bases for their selection. Five schools were randomly selected with two teachers; each selected using an opportunistic sampling technique. This technique is relevant because of the current lockdown situation in South Africa at the time of this study. The opportunistic selection method is used when dealing with social issues, where the expected participants are not easy to access (Brady, 2019). That is, the groups are either regimented, vulnerable; possess hidden characteristics, among others (Mason, 2001). Because of the current national lockdown, the participants are hard-to-find and are considered to be regimented.

\subsection{Method of Data Collection}

A semi-structured interview was used to collect data from the participants who are teachers with at least two years of experience in rural secondary schools. This type of interview, according to Reese- 
Akcakaya and Mori (2020), enables the participants to freely provide their views with a sense of confidence within the premise of the question asked. On the order hand, it also gives the researcher opportunity to engage and probe the participants/interviewees to further elaborate their thoughts in line with the onus of inquiry introduced by the researcher (Adams, 2015). This also guarantees the freedom of the participants to express their views and allow additional information to be revealed (Keeffe, Buytaert, Mijic, Brozovic' \& Sinha, 2016). The interview was conducted via WhatsApp, email,s and phone calls because there was a total lockdown in the country at the time of the study. However, the interviewees co-operated with me, and they brought out their best regarding the research question and problems with various practical solutions to the issues.

\subsection{Method of Data Analysis and Ethical Consideration}

The study adopted Socio-thematic Analysis (StA) to interpret the data collected through interviews. Omodan propounded StA in 2019 as a way of generating data by integrating the sociality of the participants in themes (Omodan, 2019c). The method was simultaneously implemented by Braun \& Clarke in thematic analysis and conversational analysis (Braun \& Clarke, 2006; Nordquist, 2019) by breaking data into relevant themes, and thereafter probing into the sociality of the participants in order to understand their ways of doing things. By doing this, the data collected was read and re-read, the coding was done, themes were identified and defined, and the data under each theme was subjected to conversational interpretation by understanding the sociality of the participants since the problem of the studies borders on how to ensure an Ubuntu kind of social space, the use of StA then becomes relevant. Ethical issues in research are very important because it helps to protect the researcher and the co-researcher from any harm during the data generation process (Dube, 2016). By doing this, all the research participants were protected by assuring them of maximum confidentiality. In the presentation of data, their identities were not revealed; instead, they were represented with pseudonyms. That is, in the below analysis, secondary school teachers were coded using SST1, SST2, $\mathrm{SST}_{3}, \mathrm{SST}_{4}, \mathrm{SST}_{5}, \mathrm{SST}_{6}, \mathrm{SST}_{7}, \mathrm{SST} 8, \mathrm{SST}_{9}$, and SST10 totalling ten participants.

\section{Data Presentation and Analysis}

The data was presented to respond to the objectives of the study, and the objectives are to explore possible challenges responsible for teachers to respond to the vacuum of COVID-19 on learners and to find workable means to ameliorate these challenges. This was done under the following sub-themes: poverty and continuous dismemberment, psycho-social stress, psychological support for teachers and learners, and sociological support for teachers and learners. This was represented in the following table.

Table 1: Thematic representation of data based on the research objectives

\begin{tabular}{|c|c|}
\hline Objectives & Analysis of sub-themes \\
\hline $\begin{array}{l}\text { 1. The challenges hindering teachers to respond to the } \\
\text { psycho-social vacuum of COVID-19 on learners. }\end{array}$ & $\begin{array}{l}\text { 1. Poverty and continuous dismemberment. } \\
\text { 2. Psycho-social stress. }\end{array}$ \\
\hline $\begin{array}{l}\text { 2. The possible solutions that could help learners } \\
\text { navigate through the challenges. }\end{array}$ & $\begin{array}{l}\text { 1. Psychological support for teachers and learners. } \\
\text { 2. Sociological support for teachers and learners. }\end{array}$ \\
\hline
\end{tabular}

3.1 Challenges hindering Teachers from Responding to the Psycho-social Vacuum of COVID-19 on Learners

\subsubsection{Poverty and Continuous Dismemberment}

South Africa's rural locations have been consistently under the unequal distribution of resources, lack of educational facilities in rural schools, and their environment is not in exemption (Omodan, Tsotetsi 
\& Dube, 2019). This may not be unconnected to poverty that has topped the list of rural characteristics. The poverty history, in this case, is unique and has a traceable link to colonialism, institutionalised racism coupled with undue exploitation (du Toit, 2017). From this, one can justify data evidence that rurally located learners are living in social and economic dismemberment. This is reflected in the following participant statements;

SST1: Most learners in rural areas are faced with poverty. I guess (digital learning is impossible for others) like here in Bongani-Lebohang, I tried creating a WhatsApp group, but not all learners had access to cellphones or Internet data.

SST3: Many rural learners have no cell/gadgets to use to access the information that is to complement the time spent at home as other teachers have created WhatsApp groups for their subjects. Even, some don't have TVs as they are from places where there's no electricity at all.

$S_{5} T_{5}$ : Some learners are unable to listen to the radio because there is no radio at home or it is currently not working. The ones who own radios lack the frequency to connect with the local radio stations.

SST2: Socioeconomic status which is the greatest barrier in rural areas, due to the lack of needed resources and equipment like poor network, high prices of data, unconducive learning environment because you will find that a house with two rooms can have seven occupants and as a result, it would not be easy to cope with studies and the lack of support from family members since many of the rural people are not educated.

SST1's utterances confirmed the fact that many rural learners are disadvantaged and unable to adapt well with any alternative to learning during COVID-19. This is because some of these learners do not own the needed electronics; even some do not have a cell-phone to use WhatsApp introduced by their teachers. In the same space, the statement from $\mathrm{SST}_{3}$ and $\mathrm{SST}_{5}$ also buttresses the fact that those learners do not have the needed electronic gadgets. Not only that, but even the use of media, such as radio and television teaching and learning, is not filling the gap for the learners because not all of them have TV and radio sets, and some of the gadgets are even faulty. Even if they have, the statement from $\mathrm{SST}_{3}$ revealed that there is no constant electricity to power their electronic sets. From these statements, one can deduce that the socioeconomic situation of rural dwellers is comatose as reflected in the statement of SST2 that the rural areas are facing problems with resources such as Internet network, access to affordable Internet data and their environment is not conducive for learning due to poor standard of living.

From the above, it is evident that the lack of resources for learners does not enhance effective teaching and learning to take place from home, and thereby, further disadvantaged the learners. This was also confirmed by the participants that poverty has a highly significance on learners and teachers.

SST4: Most learners in rural schools are very poor, so they are unable to buy and use alternative resources on the Internet to continue learning.

SST1o: Teachers were not trained to teach via media, so poor skills and experience will result in poor teaching and failing of learners.

The statements made by $\mathrm{SST}_{4}$ are a pointer to the fact that poverty and lack of access to social amenities have characterised the lives of rural learners. The statement, "Most learners in rural schools are very poor" is not contestable, and it is a reason for them not being able to possess the needed materials that are needed for them to succeed academically, most especially when the normal contact session has been put on hold. However, this is not peculiar to learners alone as teachers are also at the disadvantaged level along with the learners because they both live in the rural community and experience the same trajectories. The SST1o also indicated that many teachers lack adequate knowledge to teach with the use of the Internet. This, according to SST10, is caused by a lack of training for teachers to enable them to perform well on the virtual teaching-learning system.

\subsubsection{Psycho-social Stress}

From the general perspectives, stress and stressors are adjudged to have a significant effect on the social 
and psychological behaviours of people. This is to argue that children that are less than eighteen years of age are open to more stress resulting in various uncertainties regarding their academic and social progress. O'Donnell and Blankenship (2017) discovered that students that are open to fewer opportunities are likely to be affected socially. In the same vein, the sociality among the rural learners and their teachers shows that learners are not faring well in this time of national lockdown. The statement below complements my argument.

SST1: Some went to the extent of coming to my place to ask what they have been missing out which was shared on Whatsapp and they feel somewhat frustrated and left out which is obviously affecting them. SST2: The first challenge is that the transition from physical learning to media learning and teaching via media got learners so much mind-buggling. This will bring confusion to the learners since it will be difficult to cope with their studies due to the lack of proper skills and experience in learning and teaching via social media.

From the above conversations, one can perceive that learners in rural locations are willing to learn as they are disturbed on how they are going to meet up with their studies since some of their colleagues are working. They even go to the extent of visiting their teachers to know what they have missed out on as a result of their inability to cope well with the alternative system. SST1 confirmed that these learners feel frustrated. This is a pointer that they are mostly affected socially because they will not be able to respond well to the activities around them as a result of the uncertainty that the vacuum of COVID-19 has caused. SST2 also confirmed the fact that the learners are worried and bothered so much on the introduction of the new way of teaching (media). Socially speaking, this may be as a result of a lack of access to those facilities in the past, and mostly, they are not familiar with such a system because it is new to them. To further substantiate my argument, SST2 in her second sentence confirmed that these learners do not possess the needed skills and experiences required to adapt to the new system. In my view, this is psychological because it left them confused and worried about how to succeed in the new system.

Among many things that could affect the sociality and mind ache for these learners is the feeling that they are being taught by the teachers they are not familiar with. Allegations also exist that those who are doing online teaching are not trained teachers, instead, they are celebrities. The question then arises to ascertain how such a teacher can successfully succeed in ensuring inclusivity in his or her teaching. This suffixes in the below statements;

SST4: Most do have television sets at home to listen and watch online learning. However, the people presenting the lessons are not teachers but celebrities.

SST7: The main challenge is access to the Internet is stressing them; teachers and even the learner cannot think straight when there is bad Internet connectivity because that is more stressful.

The above statement showed that learners are not finding it easy to cope with the psycho-sociality laxity that has bridled the educational activities of the country. The statement from $\mathrm{SST}_{7}$ further showed that learners are being stressed most especially when they do not have access to quality resources such as the Internet and the Internet of things. This does not only affect learners but also teachers. The teachers are in the euphoria of meeting up with deadlines from their employer while the learners are also battling with what becomes of them if they fail to meet up with new ways of teaching and learning. In my view, this will truly affect their ways of thinking, and some may result in undue depression when solutions are not forthcoming, and there are deadlines to meet.

\subsection{Possible Solutions to Help Learners Navigate through the Challenges of COVID-19}

\subsubsection{Psychological Support for Teachers and Learners}

Taking from the above challenges, it is not out of place to suggest that learners and teachers both need to be supported to be able to respond well with the vacuum created by COVID-19 and its psychological 
effects. This is to say that not only are the learners affected, but the teachers are also affected. Therefore, supporting them to cope with the situation that is affecting their way of life is imperative. This kind of support borders more on how strong the relationships between the students and the teachers are. Such relationships according to Zendarski et al. (2020), develop positive academic and behavioural outcomes for learners and also ensure an effective and efficient way of managing social stress for both of them. Evidence from the participants are also confirmed below.

\begin{abstract}
SST5: Teachers are also affected. They need to acquire more information about COVID 19 and get psychological support first, then they will be able to impart and relate with learners effectively.

SST8: Teachers shouldn't force learners and parents to do their work for them as it is perceived in communities; however, the usee of WhatsApp groups should be strictly for support and not for teaching. SST6: Teachers should keep the learners calm (if they are able to contact them) and remind them that learning will still take place after everything is over and no one will be left out.
\end{abstract}

The participants' statements are evidence that both stakeholders need to be supported to enable them to navigate this trying time actively. In the account of $\mathrm{SST}_{5}$, teachers are not exempted from being supported. They are the first to be supported; that is, it is when teachers are stable then can they help learners to succeed. The statement made by SST8 showed that even if there are alternative means of teaching such as WhatsApp, it should be meant to support students by giving them necessary advice, motivation, and encouragement, rather than giving them an academic task that may overwhelm them. In this parlance, motivation through advising learners and encouraging learners is expedient. This was also supported by SST6 that learners need to be told to calm down and that inclusive learning will still take place. To further reiterate the need for a support system, the participants also opined that online teachers such as those who do TV and radio teaching should be included in the support system. See this:

SST4: Encouragement is needed to be given to the person currently teaching the child on TV and the same goes for radios. I think it is better to teach languages on the radio.

SST10: Some schools have mentorship programmes where each teacher hasbeen allocated 2-5 learners in which they communicate with both the learners and their parents.

The media, in this case, also need to be supported by various means of motivation. This could be in terms of adequate payment, provision of necessary equipment, among others. This will, however, enhance them to discharge their duties accordingly. Some schools are confirmed to have mentorship programmes before the pandemic where teachers are allocated students to mentor. Though this may not apply to all schools, those that have such could use it to further connect with students to lessen their psychological imbalance.

\title{
3.2.2 Sociological Support for Teachers and Learners
}

Another solution suggested to enhance the learners to cope with COVID-19 vacuum is to ensure the galvanisation of all social assets to motivate learners and teachers. This is needed to further ensure that the duo is self-fit and self-motivated, and to enable them to gain self-esteem, emotional stability, and social network. Having this will allow them to navigate social changes in their living. Research has shown that people who receive social supports are socially stable to cope with social stress (Hether, Murphy \& Valente, 2014). More evidence regarding the need for social supports appears in the statements below.

SST3: Reopen the feeding scheme while we are still facing this COVID-19 to assist those learners who come from poor families. This can be done by following all the precautions and regulations of COVID-19 keeping social distancing.

SST1: Teachers need to try to be closer to learners, support them in any way and try to educate them on the importance of following the correct measures in dealing with Covid-19 like their washing their hands 
with a sanitizer, masks, among others.

SST10: Teachers should help learners by motivating and assuring them that we will pass this pandemic and everything will get back to normal, and we can achieve that by following all precautions and regulations.

The need for sociological supports suffices in the statement made by SST3 that learners with poor backgrounds should be supported by reopening school feeding programmes to assist rural learners. This was suggested with measures to maintain the principles of social distancing as prescribed by WHO (2020a). On the other hand, teachers are also on duty to maintain amicable relationships with learners by educating and enlightening them more on the danger of COVID-19, and possible ways to prevent it. The sociality involved here is that the sociological needs cannot be achieved without ensuring good relationships between the learners and the teachers. Having established a good relationship, there is a tendency to work together without rancour. This is evidenced in the statements below.

\begin{abstract}
SST3: Winter is coming; teachers and stakeholders should work together in helping those who do not have winter clothes to donate clothes to them even shoes.

SST2: Teachers can reach out to those learners they know or who live in the same vicinity with them and provide them with one or two learning items, print any material that is useful and hand to the learners to at least get a bit of a catch-up.

SST6: As for earners who are experiencing serious social problems, teachers should assist them with food and money if they can.
\end{abstract}

To ensure that the issue of sociological need is achieved, there is a need for the concerned stakeholder to work together harmoniously. To support this, the statement of SST3 suggests that learners need to be helped by donating winter jackets and shoes as a means of supporting them socially to cope with the coming winter assumed to be dangerous with the current pandemic. Not only shelter, SST2 also comments on the plight of learners who are in need of academic materials, printing facilities, and other items as may be required to cope with the present mode of teaching and learning. At the same pace, SST6 also suggests that an extension of a kind gesture from teachers to assist rural learners with food and money will go a long way to limit various sociological problems emanating from the downturn caused by COVID-19.

\title{
4. The Findings of the Study
}

The findings for the study were reported based on the objectives of the study and the sub-themes created in the data analysis stage. The findings are represented in Table 2 below.

Table 2: Thematic representation of findings based on the research objectives

\begin{tabular}{|c|c|}
\hline Objectives & Analysis of Sub-themes \\
\hline $\begin{array}{l}\text { 1.The challenges hindering teachers fromresponding to the } \\
\text { psycho-social vacuum of COVID-19 on learners }\end{array}$ & $\begin{array}{l}\text { 3. Poverty and continuous dismemberment. } \\
\text { 4. Psycho-social stress. }\end{array}$ \\
\hline $\begin{array}{l}\text { 2. The possible solutions that could help learners navigate } \\
\text { through the challenges. }\end{array}$ & $\begin{array}{l}\text { 5. Psychological support for teachers and learners. } \\
\text { 6. Sociological support for teachers andlearners. }\end{array}$ \\
\hline
\end{tabular}

4.1 The Challenges Hindering Teachers from responding to the Psycho-social vacuum of COVID-19 on learners

\subsubsection{Poverty and Continuous Dismemberment}

From the above discussion, the result, therefore, revealed that poverty and social dismemberment are real in the rural location of South Africa. And that this has left the learners in these locations to suffer 
academically during the COVID-19 pandemic. This was confirmed by the finding of Omodan (2020a) that rural areas in South Africa have been neglected and dismembered when it comes to equal distribution of social amenities. In consonance, findings showed that poverty is mostly synonymous with rural dwellers when compared to urban and privileged counterparts (Cheteni \& Mah, 2019; Du Toit, 2017). Looking at this, one can deduce that the spirit of Ubuntu as "we are" but "not I am" (Omodan, 2019b, Omodan \& Tsotetsi, 2019) is not in operation which has placed the rural leaners at the disadvantaged level during COVID-19.

\subsubsection{Psycho-social Stress}

From the above exploration, it is evidenced that one of the challenges faced by the rural learners and, at times, the teachers, is psycho-social stress. The findings showed that learners are not coping well with the hurdles of the needed insight to respond to the psycho-social need that can help them to defeat pressures and stressors. The finding aligns with the conclusion of O'Donnell and Blankenship (2017) that non-sociable learners are open to being affected by psycho-social challenges in relation to academic development. The finding of Gulzar, Yahya, Nauman, Mir and Mujahid (2012) also confirm that frustration and academic stress hinder learners' academic success and their loss of inner minds. The finding again is in agreement with the conclusion of Qiu et al. (2020) and Hirematha et al. (2020) that the current pandemic has caused more harms than good such as; anxiety, panic disorder, and depression.

\subsection{Possible Solutions to Help Learners Navigate through the Challenges of COVID-19}

\subsubsection{Psychological Support for Teachers and Learners}

From the above analysis, one can conclude that the provision of psychological supports for both teachers and learners is needed at this critical time to emancipate both the learners and teachers from the problemss meted since the advent of COVID-19. That is, the study revealed that psychological support for teachers and learners would enhance their performance and enable both to cope with possible stress and challenges arising from the vacuum. This is in line with the conclusion of Luo, Deng and Zhang (2020) that supportive relationships among people could eradicate social and academic stressors. This is in line with the principle of oneness, support, love, and compassion, as postulated by Ubuntu philosophy (Nzimakwe, 2014)). Since there is a need for inclusive support, the place of Ubuntu that ensures interdependency and inclusivity (Bolden, 2014) is, therefore, not negotiable.

\subsubsection{Sociological Support for Teachers and Learners}

From the above discussion, one can conclude that there is a need for sociological supports, in terms of providing the social and immediate needs of both the teachers and learners. This, according to the data, will assist them in responding well with social deficiencies and challenges. That is, the study found out that sociological support for teachers and learners is one of the instruments that can nip e psycho-social challenge in the bud. This, according to House, Landis and Umberson (1988) confirms that the quality of social relatedness among people is significant in a positive direction with the sociopolitical and economical attainment. The finding of Leme, Del Prette, and Coimbra (2015) also corroborated the view that social skills such as self-esteem, civility, and social support appraisals were the best indicators of the well-being and stability of the adolescents. In order to ensure that all learners and teachers are well supported socially, the sociality among them must be ascertained. That is, there must be unity, oneness, love, collaboration, and honesty to promote Ubuntuism, which was recommended by Hoffmann and Metz (2017) as a perfect way of gingering the capability of people towards themselves. 


\section{Conclusion and Recommendations}

Leveraging on the vacuum of COVID-19 among rural learners, the challenges exist that rural secondary school learners are disadvantaged and poverty-driven. This further puts more light to support agitations for 're-memberment' of rural dwellers. As a result of the unavailability of supports, the rural secondary space is concluded to be affected by the lack of psycho-social supports to cope with COVID19 stresses. However, the need for sociological and psychological support for teachers and learners become expedient in the management of the vacuum created by the advent of COVID-19 in the rural communities of South Africa to help teachers and learners navigate the situation and make positive ways out of it. The implementation of the suggested solutions is possible when the spirit of Ubuntu is uninterruptedly made as a way of life among all the stakeholders. That is, teachers and learners must see themselves as one, irrespective of their diversities (Khomba (2011), and collaborate to achieve their aims and objectives. Based on the findings and the conclusion of the study, the following recommendations were made:

- That the stakeholders in the education sector, such as local education authorities, provincial authorities, and the department of education itself, including the government, must rally round the learners by providing an enabling environment for them to navigate this strange emergency coming from COVID-19 lockdown. This could be done by providing online social and psychological centres that could counsel learners and support them socially by giving the needed academic and social amenities such as electronics and access to affordable Internet. Among others is also the provision of palliatives that could enhance their living and enable them to think straight and respond well to their studies.

- That the stakeholders in the education sector, such as local education authorities, provincial authorities, and the department of education itself, including the government, must at the same time ensure that adequate training and support system is provided for teachers. This will enhance their skills towards undue hindrance in discharging their duties and responsibilities on the learners. The teachers themselves should at all-time integrate their motives to support the learners even at their own space of personal development. Doing this further shows the spirit of Ubuntu in their amalgamation of existence between the learners and teachers.

\section{References}

Adams, W. C. (2016). Conducting semi-structured interviews. In K. E. Newcomer, H.P. Hatry \& J. S. Wholey, Handbook of practical program evaluation. (c19, pp 492-505). Califonia: Jossey-Bass Publishers. https://www.researchgate.net/publication/301738442

Bolden, R. (2014). Ubuntu. In D. Coghlan \& M. Brydon-Miller (Eds.). Encyclopedia of Action Research. London: Sage Publications. http://dx.doi.org/10.4135/9781446294406

Brady, A. (2019). Opportunity sampling. In The SAGE Dictionary of Social Research Methods. London: SAGE Publications.

Cheteni, P., \& Mah, G. (2019). Gender and poverty in South African rural areas. Cogent Social Sciences, 5, 1-19 https://doi.org/10.1080/23311886.2019.1586080

Du Plessis, P., \& Mestry, R. (2019). Teachers for rural schools:A challenge for South Africa. South African Journal of Education, 39(1), 1- 9. https://doi.org/10.15700/saje.v39ns1a1774

Du Toit, A. (2017). Explaining the persistence of rural poverty in South Africa. United Nations Economic Commission for Africa. Addis Ababa, 27 February -1 March 2017. https://www.un.org/development/desa/dspd/wpcontent/uploads/sites/22/2019/o3/Du-Toit-2019-rural-poverty-in-SA-UNEG-2019-02-27.pdf \{Accessed o6/o5/2020.

Dube, B. (2016). A socio-religious hybridity strategy to respond to the problems of religious studies in Zimbabwe. PhD thesis, Faculty of Education, University of the Free State. http://scholar.ufs.ac.za:8o8o/xmlui/bitstream/handle/1166o/5424/DubeB.pdf?sequence=1\&isAllowed=y

Dube, B., \& D. Hlalele. (2018). Engaging in critical emancipatory research as an alternative to mitigate school violence in South Africa. Education Research for Social Change, 7(2), 74-86. http://dx.doi.org/10.17159/22214070/2018/v7i2a5 
Ebrahim, S.H., Ahmed, Q.A., Gozzer, E., Schlagenhauf, P., \& Memish, Z.A., 202o. Covid-19 and community mitigation strategies in a pandemic. BMJ 368. https://doi.org/10.1136/bmj.m1o66

Gulzar, S., Yahya, F., Nauman, M., Mir, Z., \& Mujahid, S. H. (2012). Frustration among University Students in Pakistan. International Research Journal of Social Sciences, 1(4), 1-15. http://www.isca.in/IJSS/Archive/v1/i4/2.ISCA-IRJSS2012-058

Hirematha, H., Kowshik, C. S. S., Manjunathb, M., \& Shettar, M. (2020). COVID 19: Impalockdownk-down on mental health and tips to overcome. Asian Journal of Psychiatry, 51, 1-2. https://doi.org/10.1016/j.ajp.2020.102088

Hlalele, D. (2012). Social justice and rural education in South Africa. Perspectives in Education, 30(1), 111-118. https://www.researchgate.net/publication/289638524

Hoffmann, N., \& Metz, T. (2017). What can the capabilities approach eearn from an Ubuntu Ethic? A relational approach to development theory. World Development, 97, 153-164. https://doi.org/10.1016/j.worlddev.2017.04.010

House, J. S., Landis, K. R., \& Umberson, D. (1988). Social relationship and health. Science, New Series, 241(4865), 540-545. http://www.jstor.org/stable/1701736

Hughes, A. (2020). Positioning indigenous knowledge systems within the Australian mathematics curriculum: Investigating transformative paradigms with Foucault, discourse: Studies in the cultural politics of education, https://jerrcd.org/10.1080/o1596306.2020.1715345

Jolley, D. R. 2011. Ubuntu: A person is a person through other persons. Master's degree project. Southern Utah University. https://www.suu.edu/hss/comm/masters/capstone/thesis/jolley-d.pdf. 04/05/2020.

Keeffe, J. O., Buytaert, W., Mijic, A., Brozovic', N., \& Sinha, R. (2016). The use of semi-structured interviews for the characterisation of farmer irrigation practices. Hydrology and Earth System Science, 20, $1911-1924$. http://dx.doi.org/10.5194/hess-20-1911-2016

Khomba, K. J. (2011). Redesigning the balanced scorecard model: An African perspective. PhD thesis, University of Pretoria, South Africa.

Lefa, B. J. 2015. The African philosophy of Ubuntu in South African education. Master thesis. Cape Peninsula University of Technology. https://www.researchgate.net/publication/274374017_The_African_Philosophy _of_Ubuntu_in_South_African_Education/download, 05/05/2020.

Leme, V. B. R., Del Prette, Z. A. P., \& Coimbra, S. (2015). Social skills, social support and well-Being in adolescents of different family configurations. PaidéiaRibeirãoPreto, 25(60), 9-18. https://doi.org/10.1590/198243272560201503

Luo, Y., Deng, Y., \& Zhang, H. (2020). The influences of parental emotional warmth on the association between perceived teacher-student relationships and academic stress among middle school students in China. Children and Youth Services Review, 1-44. https://doi.org/10.1016/j.childyouth.2020.105014

Mason, J. (2002). Sampling and selection in qualitative research. In Qualitative Researching (2nd ed). London: Sage.

Msila, V. (2008). Ubuntu and school leadership. Journal of Education, 44, 68-84. http://joe.ukzn.ac.za/Libraries/No_44_Jul_20o8/Ubuntu_and_school_leadership.sflb.ashx

Nzimakwe, T. I. (2014). Practising Ubuntu and leadership for good governance The South African and continental dialogue. African Journal of Public Affairs, 7(4), 30-41. http://hdl.handle.net/2263/58143

O'Donnell, C., \& Blankenship, B. (2017). Status frustration among college students: The relationship between socioeconomic status and undergraduate performance. Deviant Behaviour, 39(6), 679-693, https://doi.org/10.108o/01639625.2017.1286197

Omodan, B. I., \& Tsotetsi, C. T. (2018). Student-teacher relationships as panacea for students' academic performance in Nigerian secondary schools: An attachment perspective. Journal of Social Studies Education Research, 9(4), 82-101. https://jsser.org/index.php/jsser/article/view/348/340

Omodan, B. I. (2019). A strategy to enhance crisis management between students and university authorities in Nigeria. PhD thesis, University of the Free State, South Africa.

Omodan, B. I. (2019). Defacing Machiavellianism in university politics: A discourse to reconstruct leadership through Ubuntu. African Renaissance, 16(4), 33-51. http://doi.org/10.31920/2516-5305/2019/16n1a2

Omodan, B. I.,. \& Tsotetsi, C. T. (2019). Framing Ubuntu philosophy to reconstruct principals' behaviour and teachers' effectiveness in secondary Schools. Journal of Education Research and Rural Community Development, 1(1), 25-45. https://jerrcd.org/article/view/19647/13241

Omodan, B. I., \& Dube B. (2020). Towards de-colonial agitations in university classrooms: The quest for Afrocentric pedagogy. International Journal of Learning, Teaching and Educational Research, 19(4), 14-28. https://doi.org/10.26803/ijlter.19.4.2

Omodan, B. I. (2020). The vindication of decoloniality and the reality of COVID-19 as an emergency of the unknown in rural universities. International Journal of Sociology of Education. 20, 126.http://doi.org/10.17583/rise.2020.5495 
Qiu, J., Shen, B., Zhao, M., Wang, Z., Xie, B., \& Xu, Y., 2020. A nationwide survey of psychological distress among Chinese people in the COVID-19 epidemic: implications and policy recommendations. General Psychiatry 33 (2), 1-4. https://doi.org/10.1136/gpsych-2020-100213

Ramose, M. B. (1999). African philosophy through Ubuntu. Mond Books: Harare.

Reese-Akcakaya, R. L., \& Mori, D. L. (2020). The assessment of readiness and consent for hormone therapy (ARCH): A semi-structured interview for use with transgender and gender nonconforming individuals. Psychosomatics, 1-23. doi: https://doi.org/10.1016/j.psym.2020.02.008.

Republic of South Africa. (1996). Act No. 84, 1996: South African Schools Act, 1996. Government Gazette, $377(1715$ November 15 .

Sarpong, D., Bi, J., \& Amankwah-Amoah, J. A. (2016). On the nurturing of strategic foresight: The Ubuntu perspective. Futures, 75, 14-23. http://dx.doi.org/10.1016/j.futures.2015.10.007

Tutu, D. (1999). No future without forgiveness. London: Rider.

Tworeck, C., Hemminga, D., Huber, D., \& Dhillon, D. (2015). The Ubuntu philosophy as a management strategy. file://C:/Users/bolab/Downloads/UbuntuasaManagementStrategy.pdf. Acessed 04/05/2020.

Varalakshmi, R., \& Arunachalam, K. (2020). COVID 2019: Role of faculty members to keep mental activeness of students. Asian Journal of Psychiatry, 51, 1-2. https://doi.org/10.1016/j.ajp.2020.102091

WHO, 2020. Coronavirus disease 2019: (COVID-19) situation report- 46. URL https://www.who.int/docs/defaultsource/coronaviruse/situation-reports/20200306- sitrep-46-covid-19.pdf?sfvrsn=96bo4adf_2 (Accessed 3.31.20).

WHO, 2020. Pneumonia of unknown cause: China. URL https://www.who.int/csr/don/o5- january-2020pneumonia-of-unkown-cause-china/en/ (accessed 3·31.20).

Wuhan Municipal Health and Health Commission. Briefing on the current pneumonia epidemic situation in our city. http://wjw.wuhan.gov.cn/front/web/showDetail/2019123108989

Zeea, M., De Breea, E., Hakvoortb, B., \& Koomena, H. M. Y. (2020). Exploring relationships between teachers and students with diagnosed disabilities: A multi-informant approach. Journal of Applied Developmental Psychology, 66, 1-12. https://doi.org/10.1016/j.appdev.2019.101101

Zendarski, N., Haebicha, K., Bhide, S., Quek, J., Nicholsona, J. M., Jacobs, K. E., Efrona, D., \& Sciberras, E. (2020). Student-teacher relationship quality in children with and without ADHD: A cross-sectional community-based study. Early Childhood Research Quarterly, 51(2), 275-284. https://doi.org/10.1016/j.ecresq.2019.12.006 